\title{
Práticas de pesquisa na escola básica: discutindo alguns encaminhamentos metodológicos
}

\author{
Renata Cristina Oliveira Barrichelo Cunha \\ Programa de Pós-Graduação em Educação da Universidade Metodista de Piracicaba - SP - Brasil \\ reccunha@unimep.br
}

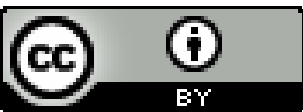

EDUCAÇÃO: Teoria e Prática, Rio Claro, SP, Brasil - elSSN: 1981-8106

Está licenciada sob Licença Creative Common

\section{Resumo}

O artigo apresenta e discute o trabalho de pesquisa e formação em regime de colaboração em uma escola da rede pública estadual do interior paulista que atende alunos do Ensino Fundamental II e Ensino Médio. Acompanhando as atividades de trabalho pedagógico coletivo (ATPCS) com o objetivo de compreender como os espaços coletivos vão se constituindo e sendo apropriados como experiências de formação pelos professores e gestores, o texto problematiza, a partir dos registros audiogravados e transcritos, aspectos teórico-metodológicos importantes para a construção e acompanhamento dessa pesquisa, em particular, e outras interessadas pela pesquisa colaborativa: a relação entre pesquisadores externos e professores da escola básica; a formação de professores como contrapartida da pesquisa; a construção de vínculos e a colaboração; a interlocução teoria e experiência; a socialização e interpretação dos registros do trabalho; e a relação autoria e coautoria. As análises apontam para a necessidade de aproximar as práticas de pesquisa do cotidiano de formação nas ATPCs e instituir uma comunidade interpretativa, por meio do trabalho coletivo, que seja (re)orientadora das práticas pedagógicas da escola e da própria pesquisa, articulando pontos de vista, vozes e diferenças.

Palavras-chave: Pesquisa na escola básica. Metodologia de pesquisa. Formação de professores. Trabalho docente coletivo.

\section{Research practices at elementary school: discussing some methodological implementations}

\begin{abstract}
This article presents and discusses the research and formation work as a collaborative program at a public school in the interior of San Paulo State which serves students of Elementary and High School Level. By following the activities of collective pedagogical work, with the objective of understanding how the collective spaces are constituted and used as experiences of training by teachers and board members, the test put the focus on important theoretical and methodological aspects for the construction and monitoring of this research itself and others interested in collaborative research using audio record and transcribed data: the relationship between external researchers and teachers of elementary school; the
\end{abstract}


teachers training as a counterpart of the research; the construction of ties and collaboration between the parts; the interaction between theory and experience; the socialization work and the interpretation of recordkeeping activities; the relationship between authorship and co-authorship. The analysis point to the need of bringing together the daily research practices of training collective work and also to the need of setting up an interpretative community through collective work that reorients the pedagogical practices of the school and the research itself and articulates the different points of view.

Keywords: Research at elementary school. Research methodology. Teachers training. Collective teaching work

\section{Prácticas de investigación en la escuela básica: discutiendo algunos encaminamientos metodológicos}

\section{Resumen}

El artículo presenta y discute el trabajo de investigación y formación en régimen de colaboración en una escuela de la red pública estadual del interior paulista que atiende a alumnos de la Enseñanza Fundamental II (Enseñanza Secundaria) y Enseñanza Media (Bachillerato). Acompañando las actividades de trabajo pedagógico colectivo (ATPCs) con el objetivo de comprender como los espacios colectivos van constituyéndose y siendo apropiados como experiencias de formación por los profesores y gestores, el texto problematiza, a partir de los registros audiograbados y transcritos, aspectos teóricometodológicos importantes para la construcción y acompañamiento de esa investigación, en particular, y otras interesadas por la investigación colaborativa: la relación entre investigadores externos y profesores de la escuela básica; la formación de profesores como contrapartida de la investigación; la construcción de vínculos y la colaboración; la interlocución teoría y experiencia; la socialización e interpretación de los registros del trabajo; y la relación autoría y coautoría. Los análisis apuntan para la necesidad de aproximar las prácticas de investigación al cotidiano de formación en las ATPCs e instituir una comunidad interpretativa, por medio del trabajo colectivo, que sea (re)orientadora de las prácticas pedagógicas de la escuela y de la propia investigación, articulando puntos de vista, voces y diferencias.

Palabras clave: Investigación en la escuela básica. Metodología de investigación. Formación de profesores. Trabajo docente colectivo.

\section{Introdução}

A discussão apresentada neste artigo é fruto de reflexões e análises sobre os encaminhamentos metodológicos iniciais, decorrentes de um projeto de pesquisa financiado pelo CNPq/CAPES e iniciado em 2012, que tem como objetivo principal compreender como os espaços coletivos da escola, especialmente as atividades de trabalho pedagógico coletivo (ATPCs) e Conselhos, vão se constituindo e sendo apropriados pelos professores e equipe gestora como experiências de formação. 
Nos limites deste texto apresentamos a forma como estamos concebendo esse trabalho de pesquisa e formação em regime de colaboração na escola e de que modo estamos aproximando as práticas de pesquisa do cotidiano de formação nas ATPCs.

Para os professores dessa escola é a primeira vez que convivem com um grupo de pesquisadores na unidade escolar, e compreender o sentido e os objetivos da pesquisa, na nossa perspectiva, é fundamental para que possam vir a se reconhecer como coautores de nossa produção e como pesquisadores de sua própria prática.

Levamos em consideração, na construção do presente texto, a perspectiva de Duarte (2002, p.140):

\begin{abstract}
Uma pesquisa é sempre, de alguma forma, um relato de longa viagem empreendida por um sujeito cujo olhar vasculha lugares muitas vezes já visitados. Nada de absolutamente original, portanto, mas um modo diferente de olhar e pensar determinada realidade a partir de uma experiência e de uma apropriação do conhecimento que são, aí sim, bastante pessoais. Contudo, ao escrevermos nossos relatórios de pesquisa ou teses de doutorado, muitas vezes nos esquecemos de relatar o processo que permitiu a realização do produto. É como se o material no qual nos baseamos para elaborar nossos argumentos já estivesse lá, em algum ponto da viagem, separado e pronto para ser coletado e analisado; como se os "dados da realidade" se dessem a conhecer, objetivamente, bastando apenas dispor dos instrumentos adequados para recolhê-los. Não parece ser assim que as coisas se passam. A definição do objeto de pesquisa assim como a opção metodológica constituem um processo tão importante para o pesquisador quanto o texto que ele elabora ao final.
\end{abstract}

Sendo assim, narrar as escolhas e dificuldades desse percurso, bem como alguns achados, pode ajudar outros colegas pesquisadores envolvidos com a pesquisa na escola básica a problematizarem as possibilidades de se produzir conhecimento sobre/na/com os professores nas escolas.

Isso nos parece relevante frente à nossa própria necessidade de sistematizar o percurso da pesquisa, mas, também, do ponto de vista de orientadores de trabalhos de conclusão de curso, iniciação científica, dissertações e teses e, consequentemente, leitores de trabalhos científicos e membros de bancas de qualificação e defesa, que defendem que para fazer pesquisa na escola é preciso respeitar esse espaço, valorizar os conhecimentos e saberes nele produzidos, conhecer sua dinâmica, construir um vínculo de confiança com os profissionais da escola.

Não é incomum nos depararmos com trabalhos que levantam informações nas escolas - observações de salas de aula, entrevistas com professores, participação em ATPCs etc. - de maneira fragmentada e descontextualizada, e que sistematizam as análises sem 
considerar as relações estabelecidas entre pesquisadores e sujeitos e sem problematizar as próprias condições de produção e interpretação dos dados.

A pesquisa na escola, como a formação, é uma atividade relacional, sensível ao encontro, ao outro. Almeida (2001) ao destacar a importância das relações interpessoais na formação docente, argumenta que o olhar atento, o ouvir ativo e o falar autêntico são condições para a constituição de um grupo. Entendemos que essas condições também são aplicadas à construção do vínculo entre pesquisadores e profissionais e sua presença na escola, pois, do contrário, o desenvolvimento da investigação vai se reduzindo ao levantamento de informações, tratamento de dados, publicação de resultados alheios às necessidades formativas, possibilidades de contribuição e interpretação das situações pelos sujeitos da escola.

\section{Estar na escola com os professores: colaboração e coautoria}

A pesquisa vem sendo desenvolvida em uma escola da rede pública estadual de uma cidade do interior paulista que atende alunos do Ensino Fundamental II e Ensino Médio. A escola, localizada em um bairro distante $6 \mathrm{~km}$ do Centro, atende 1003 alunos divididos em três períodos e conta com, aproximadamente, 40 professores. Segundo caracterização do projeto político-pedagógico (PPP) da escola, do ano de 2011, a unidade escolar está inserida numa comunidade bastante carente e muitos moradores e pais de alunos não têm uma profissão definida, o que os obriga a trabalhar em vários serviços temporários e informais. Parte das famílias é atendida pelos programas sociais do governo federal (Bolsa Família e Passe Escolar), além de contar com programas municipais.

Por que escolhemos essa escola e não outra? Conhecemos essa escola por relatos de professores e supervisores de ensino e, ouvindo a diretora da escola em palestras e apresentações em seminários de práticas educativas, tratando da diminuição da violência escolar na unidade, dos projetos de trabalho e dos Conselhos Participativos de Classe, que reúnem professores, pais e alunos da escola. A escola é a única no município que desenvolve os Conselhos de Classe contando com a presença e participação de alunos e pais. Também é uma escola que assume as ATPCs como espaços e tempos de formação dos professores e 
concebe os professores coordenadores (PCs) como mediadores da formação centrada na escola.

Compreendemos a formação centrada na escola como aquela que

[...] acontece no contexto de trabalho, privilegiando a colaboração, a interlocução sobre as práticas, as necessidades e os interesses dos professores que participam da construção e da gestão do plano de formação e são corresponsáveis pelo seu desenvolvimento (CUNHA; PRADO, 2010, p.104).

Nessa perspectiva, defendemos que os PCs são os interlocutores privilegiados entre os professores em suas reflexões sobre a prática e responsáveis por promover a formação continuada dos professores no interior da escola. Professores e PCs, negociando pontos de vista e responsabilidades, bem como compartilhando necessidades, interesses e contribuições, vão formando-se na reciprocidade, produzindo uma coformação capaz de fortalecer valores comuns, produzir incertezas pertinentes, alimentar o diálogo entre os saberes e as circunstâncias, gerando novas coerências (CUNHA; PRADO, 2008).

Para atender nossos objetivos de pesquisa, portanto, precisávamos de uma escola com essas características, já que partíamos do pressuposto que os espaços coletivos são potencialmente formativos e que uma parte significativa da formação e desenvolvimento profissional do professor se dá na escola onde trabalha.

Essa é uma etapa importante da pesquisa: a definição da escola onde a investigação será desenvolvida. A escolha de uma escola e não outra não pode ser concebida de maneira aleatória ou fruto de conveniências do pesquisador. Dependendo dos objetivos da pesquisa e sua questão orientadora, a escolha de uma escola repercute na produção e análise dos dados e, portanto, dos resultados e contribuições da pesquisa.

Outro aspecto importante diz respeito à abordagem e aproximação com a escola. Nosso contato inicial foi feito com a equipe gestora, formada por uma diretora, uma vicediretora e PCs (um para o Ensino Fundamental e outro para o Ensino Médio), responsáveis pelas ATPCs.

Apresentamos o projeto de pesquisa, nossa disponibilidade e os termos de consentimento livre e esclarecido. Procuramos ouvir suas dúvidas, preocupações, e questões sobre o desenvolvimento do cronograma de trabalho, bem como compreender a rotina da escola e as dinâmicas das ATPCs. Como pesquisadores, quando nos apresentamos à escola, temos em mente uma idealização da rotina e do trabalho que pode ser desenvolvido ali a 
partir de outras experiências que tivemos como professores e pesquisadores. No entanto, cada unidade escolar tem suas peculiaridades em relação à gestão e organização do trabalho pedagógico, comunidade escolar, prioridades, modos de funcionamento. Ouvir a narrativa sobre o cotidiano da escola é fundamental para que possamos ajustar as expectativas, nos incluirmos na dinâmica da escola sem atropelos, respeitando seu modo de organização. Adequações na metodologia da pesquisa, às vezes tão necessárias, só são possíveis a partir das contribuições de gestores, professores, funcionários, alunos.

Aprendemos com Almeida (2000) que para que uma relação interpessoal seja produtiva é preciso ouvir o outro e demonstrar consideração e empatia. Em seu texto, a autora se refere à relação entre coordenadores e professores no processo de formação continuada na escola, mas a nós parece que essa relação diz respeito, também, à relação a ser constituída entre pesquisadores e professores. Uma relação sensível ao outro e disponível a aceitá-lo como pessoa que é. Concordamos que um sujeito de pesquisa só pode apresentar-se sem medo e constrangimento se ele se sentir aceito, valorizado e compreendido.

Como apontado por Mattos (1995, p.113), o pesquisador precisa confiar que o "professor será fiel à parceria, que estará aberto às perguntas da pesquisa; tem de acreditar que o professor sabe sobre sua prática (...); que o professor pode descrever e solucionar problemas aos quais os pesquisadores não estavam atentos".

No caso de nossa proposta de acompanhar as ATPCs, de nossas primeiras conversas com a equipe gestora descobrimos que as ATPCs eram organizadas em três horários, ao longo da semana, e a participação dos professores variava de acordo com sua carga horária de aulas na escola. Cada professor frequentava os horários de ATPC que melhor atendia sua rotina de trabalho e essa era uma flexibilidade interessante da equipe gestora, que admitia que a participação dos professores precisava dar-se em condições de trabalho favoráveis, o que significava considerar horários convenientes para sua jornada de trabalho e vida pessoal.

Combinamos, então, que esses encontros seriam mediados pelos PCs, como já se fazia, exceto um deles, que seria dirigido por duas pesquisadoras do projeto. Esse modo de organização foi decidido com a equipe gestora para atender duas necessidades: a primeira, para podermos acompanhar o processo de trabalho coletivo com a mediação dos PCs (esse 
percurso foi e está sendo registrado em Cadernos de Registros pelos próprios professores e PCs e também em áudio para transcrição e análise) com vistas à compreensão dos modos de organização e socialização das experiências e teorias do grupo; em segundo lugar, para oferecer aos pesquisadores a oportunidade de participar ativamente da rotina da escola e da constituição do trabalho coletivo como instância de formação.

Com relação às ATPCs com as pesquisadoras, que aconteceram quinzenalmente, totalizando 14 encontros de 90 minutos cada, ao longo de 2012, as discussões, acordadas entre pesquisadores, gestores e professores, a partir do diagnóstico de necessidades da escola, giraram em torno das dificuldades de leitura dos alunos, da falta de interesse pelos livros e as contribuições da leitura literária não só para a constituição da subjetividade e cidadania de adolescentes e jovens, mas também para a experiência de formação dos próprios professores. Para aprofundar a temática, recorremos à leitura de capítulos de dois livros de Michele Petit: “Os jovens e a leitura" (2009) e "A arte de ler" (2010), bem como de contos e crônicas.

Como já destacado, estar na escola e pesquisar o cotidiano escolar exige certos cuidados e um tipo de atenção especial dos pesquisadores. Cada escola tem uma dinâmica própria, uma rotina, uma maneira de funcionamento sensível às interferências e a presença de estranhos. Receber pesquisadores externos com uma proposta de acompanhamento, interpretação e análise do que se passa nos espaços coletivos exige a construção de vínculos de confiança sólidos, pois não faz parte da cultura da nossa escola pública contar com pesquisadores e trabalhar com uma dimensão investigativa das práticas.

Cabe destacar que não foram os professores ou os gestores quem nos convidaram para ir à escola com uma demanda específica; fomos nós quem nos apresentamos interessados nas suas experiências.

Dias-da-Silva (2001, p.160-161) destaca que a viabilidade da realização de uma pesquisa na escola pressupõe "toda uma fase de trabalho dedicada à sensibilização de professores e equipe técnica que, acostumados à desqualificação que são alvos em muitas pesquisas educacionais" resistem e desconfiam da proposta de pesquisa. Admite que "não é fácil convencer os professores que 'fazer teses' e 'escrever artigos' é nosso trabalho e função e não fruto de oportunismo interesseiro e individualista dos membros da universidade". 
No nosso caso, essa fase de sensibilização foi relativamente rápida, pois com o apoio da equipe gestora da escola, logo os professores se deram conta do já apontado por Cunha e Aragão (2012, p.11) em outro contexto de pesquisa: "na relação entre universidade e escola (...) todos os envolvidos no trabalho são capazes de relacionar informações do campo da prática e do campo da teoria, de modo a fundamentar as ações e os pensamentos". Nesse sentido, "a interlocução é peça-chave no desenvolvimento da reflexividade, na revisão dos pontos de vista, ressignificação das posições assumidas, negociação de perspectivas, construção de consensos provisórios, no diálogo teoria-experiência" (CUNHA; ARAGÃO, 2012, p.15).

Cabe descrevermos os passos dados na construção e consolidação desses vínculos. Apresentamo-nos no início de 2012, na semana de planejamento. Nesse momento, tivemos o cuidado de narrar nossa trajetória profissional - todos nós fomos professores da escola básica antes de atuarmos no ensino superior - e compartilhar o projeto de pesquisa com o grupo. Cada professor recebeu uma cópia do projeto e nos colocamos à disposição para tirar as dúvidas de cada um pessoalmente ou por email. Compreendemos que socializar o projeto de pesquisa é o primeiro passo para que os professores possam confiar no grupo de pesquisadores. É preciso que os professores, na escolha de participar ou não, compreendam não só os objetivos da pesquisa, mas seus pressupostos, marcos teóricos, previsão de encaminhamentos e expectativas.

Mas o que tínhamos para oferecer à escola? Qual a contrapartida para o grupo de professores que nos acolheram? Por que uma escola e os profissionais que nela trabalham vão abrir suas portas e dividir seu tempo, suas preocupações, seus modos de pensar, fazer e sentir? Entendemos que a contrapartida da pesquisa desenvolvida na escola é a formação dos professores - a troca entre conhecimentos produzidos na escola e na universidade - e o fortalecimento de uma reflexão e ação que permita produzir novos e outros sentidos para o trabalho docente e para a própria pesquisa.

Sendo assim, nesse contexto das ATPCs das quais participamos, temos trabalhado a favor de um processo de formação e pesquisa onde pesquisadores externos e professores da escola compartilham, discutem, confrontam e produzem em colaboração conhecimentos e saberes da própria formação e exercício da profissão. Pesquisadores externos e professores 
da escola, portanto, que atuam como colaboradores na revisão de suas práticas de ensino e de pesquisa.

A formação como contrapartida ou contribuição do processo de pesquisa não pode ser confundida com aulas e cursos, tampouco como imposição de uma outra maneira de organizar as práticas da escola. Aliás, não concebemos a formação centrada na escola com o intuito de suprir lacunas da formação inicial ou atualizar conhecimentos em nome de um mundo em constante transformação. Estamos nos orientando por uma concepção de formação que valoriza a reflexão sobre a prática e que é marcada, como destacado por Sacristán (1998), pelo seu caráter de complexidade, imprevisibilidade, singularidade e conflitos de valores.

Fragmento da ATPC de 08/05/2012 revela como os professores foram se apropriando da proposta e dos encontros (os nomes são fictícios, respeitando o sigilo combinado):

Profa Eliana (Matemática): Quando os encontros foram propostos, eu (como a maioria) acreditava que seria algo muito mais da ordem da obrigação que da ordem do prazer, do gosto. Ora, percebi que ocorreu justamente o contrário, é só perceber como a hora passa rapidamente em nossos encontros! Ouvir as experiências dos outros tem me ajudado.

Profa Daniela (Português): Sim, porque é por gosto, não é algo como: você deve fazer! E então você responde: Não quero!

Prof a Paula (Matemática): O lado bom dos encontros, para mim, são as leituras. Porque se eu não estivesse aqui fazendo esse tipo de leitura, eu estaria em minha casa ou em outro local, fazendo algo exclusivamente de minha área somente. Compreendem? Eu fico muito focada naquele mesmo assunto e não abro possibilidades para ler outras coisas, então, particularmente para mim, as leituras dos encontros têm sido.... (...) Reconheço que quando foi proposta a leitura do livro A Casa de Papel [DOMINGUEZ, 2006], eu pensei: Meu Deus! Quando é que lerei esse livro? Mas eu li, e li muito rápido, porque eu não consegui parar de ler!

Em 19/06/2012 a Profa Sueli, de Português, destaca:

Achei que uma das coisas mais legais em nossos encontros foi que nós tivemos um momento até então inédito: de estar com colegas que nós somente encontraríamos no corredor, aonde somente iríamos nos cumprimentar ou nos conhecer apenas de nomes ou por conversas muito rápidas. E algo que me enriqueceu muito foi o convívio com o grupo. Pensei também que por conta disso, como ficou muito mais gostoso o estar juntos, o estudar juntos...

Os encontros foram apropriados como encontros, ou seja, oportunidades de estar junto, pensar junto, decidir junto. Os professores puderam valorizar o intercâmbio entre si e 
com os pesquisadores e compreender que a formação é produzida no grupo e por meio do trabalho coletivo.

Outro fragmento de 08/05/2012 revela uma outra maneira de apropriação da ATPC como espaço e tempo de formação:

Pesquisadora 1: Alguém tinha a expectativa de que os encontros fossem uma espécie de curso?

Prof ${ }^{a}$ Sueli (Português): Eu acreditei que seria algo mais maçante, mais... Profó Daniela (Português): Com bastante teoria.

Pesquisadora 2: Sabe o que eu tenho pensando, que me chama muita atenção e que me dá prazer em vir aos encontros? É que a teoria está presente o tempo todo. Eu consigo visualizar nas experiências o quanto nós vamos conseguindo articular, pois se somente ficássemos nas experiências e a teoria não se fizesse presente, eu tenho certeza de que eu não estaria empolgada de estar aqui. Então, a teoria aparece de outro jeito e o que é interessante é que não é de forma maçante.

Pesquisadora 1: Sabem por que? Porque essa teoria que aparece não mantém o grau de exterioridade que estamos acostumados a lidar quando estamos na universidade etc. Também não estamos lidando com as chamadas capacitações da Diretoria de Ensino. O que estamos conseguindo instituir nas ATPCs (e imagino que não é exclusividade desta ATPC) é poder produzir teoria (a nossa própria teoria, inclusive, pensando o próprio trabalho), articulada à própria experiência. Porque uma formação continuada na escola (pois o que estamos desenvolvendo é uma modalidade, vocês podem possuir experiências que confirmem outras possibilidades), é uma formação que precisa ser sustentada pela experiência e pela prática, algo que costuma ser desvalorizado na universidade e, às vezes, nas próprias ATPCs. Canso de ouvir professores reclamando das ATPCs e isso por que? Porque só se fala da prática, é a cultura da lamentação, mas é também o sentimento de impotência que a maior parte de nós se deixa levar (porque há muitas coisas que não damos conta mesmo e não conseguimos responder). Então, essa experiência de formação compartilhada na ATPC precisa partir, precisa levar em consideração o universo experiencial, as nossas expectativas, práticas, as nossas narrativas sobre a prática, no entanto, precisamos extrapolar isso, produzindo teoria e dialogando com outras referências que cada um de nós traz, a partir de sua área de conhecimento, cultura geral, formação etc.".

Prof. Carlos (Professor Coordenador): Essa é a palavra-chave: produção. A produção que nós somos capazes. Na escola se perdeu um pouco a visão crítica sobre tudo, então, a ATPC é um muro de lamentações, você sempre espera por alguém que irá falar uma verdade que sirva para você, isso na escola. Quando você vai para fora (para a Diretoria de Ensino ou outro lugar), a pessoa que fala carrega o estandarte da verdade absoluta: eu já me peguei discutindo com professores em ATPCs onde afirmavam: - Mas falaram que é assim! A diretora falou! O supervisor falou que é assim! Ou seja, a pessoa não possui o mínimo senso crítico, nem se questiona no sentido de se perguntar: - Mas, por que é assim? Ou: - E se isso fosse feito de outra maneira, não seria melhor? Acredito que a escola perdeu muito desse senso crítico, creio que é por isso que, em nossos encontros, todos 
estão entusiasmados, não há uma ordem ou verdade a ser seguida, nós é que estamos produzindo o que será certo e errado, a partir de nosso ponto de vista.

Christov (1998, p.31-33) nos ajuda a compreender essa relação teoria-prática ao destacar que "teoria e prática são diferentes, mas andam juntas: às vezes de forma desapercebida, às vezes de forma refletida (...). Entre a teoria de um autor que queremos assumir e a prática que pretendemos transformar com esta teoria existe a nossa teoria".

Admitir que pesquisadores e professores produzem teorias a partir das suas experiências e interações é coerente com a perspectiva de que nossas teorias vão sendo construídas na medida em que as experiências vão sendo lidas e perguntas vão sendo dirigidas à prática. Isso significa que a possibilidade de ler as nossas próprias experiências é proporcional ao interesse e investimento para compreendermos os autores e questioná-los para compreendermos a prática.

Nesse sentido, concordamos com Sacristán e Pérez Gómez (1998, p.10) quando afirmam que a formação

[...] é fruto da reflexão sobre a ação, ajudada por quanta tradição do pensamento tenha sido capaz de dar sentido à realidade educativa. Os professores/as serão profissionais mais respeitados quando puderem explicar as razões de seus atos, os motivos pelos quais tomam umas decisões e não outras, quando ampararem suas ações na experiência depurada de seus colegas e quando souberem argumentar tudo isso numa linguagem além do senso comum, incorporando as tradições do pensamento institucionalizado. Para transformar, é preciso ter consciência e compreensão das dimensões que se entrecruzam na prática dentro da qual nos movemos.

Como já apontado por Zeichner (1998), nesse processo buscamos eliminar a separação entre o mundo dos pesquisadores acadêmicos e o mundo dos professores, estabelecendo um diálogo que permita uma interlocução teórica e um melhor entendimento do contexto da escola. Há que se admitir, no entanto, que mesmo que acadêmicos e professores trabalhem como parceiros, cada um reconhecendo e respeitando as contribuições do outro, não há igualdade absoluta, uma vez que trazem diferentes conhecimentos e experiências nessas trocas.

Lüdke (2009) recorda que apesar do esforço por relações menos hierárquicas, e admitindo que os professores são interlocutores e não simplesmente informantes, são os 
pesquisadores externos quem propõem a pesquisa, interpretam os dados e são os autores do texto final.

De fato, fomos nós quem procuramos a escola com o objetivo de compreender como os espaços coletivos vão se constituindo e sendo apropriados como experiências de formação e somos nós quem estamos construindo as análises para socializá-las. No entanto, as relações estabelecidas na escola, se não manifestam um respeito incondicional pelos profissionais que nela atuam e não têm um caráter de colaboração não podem também contribuir com a formação dos professores e dos pesquisadores.

Isto porque na colaboração,

[...] ao trabalharem juntos, os membros de um grupo se apoiam, visando atingir objetivos comuns negociados pelo coletivo, estabelecendo relações que tendem à não-hierarquização, liderança compartilhada, confiança mútua e co-responsabilidade pela condução das ações (DAMIANI, 2008, p.215).

Estamos assumindo a concepção de ação colaborativa ou parceria colaborativa entre universidade e escola básica na perspectiva anunciada por Giovani (1998), que a compreende como um processo de formação continuada de professores e pesquisadores, com ênfase no trabalho coletivo, capaz de articular questões práticas e problemas teóricos que, mediante um processo de estudo e investigação, pode ampliar o conhecimento e a compreensão da realidade escolar e favorecer o desenvolvimento dos vários profissionais.

Tanto os professores como os pesquisadores têm, em ambas as instituições, a partir do diálogo, suas ações redimensionadas, pois o desenvolvimento profissional, a renovação das práticas de ensino e pesquisa e o acesso a outros campos de conhecimentos e experiências só se faz possível no intercâmbio estabelecido.

Esse intercâmbio, para ser valorizado e tematizado na pesquisa, tem sido por nós registrado em diários de campo e audiogravação. Ao longo do 10 semestre de pesquisa tivemos, inclusive, a preocupação com o significado que o gravador poderia ter não só no grupo que conta com os pesquisadores, mas nas demais ATPCs mediadas pelos PCs. Socializamos dois textos, baseados em pesquisas desenvolvidas por alguns de nós em uma rede de ensino de outro município e encaminhados para apresentação em eventos (XXXX, 2012a, XXXX, 2012b - supressão da identificação de autoria). Nosso objetivo era mostrar como as transcrições das falas dos diversos sujeitos e atores das pesquisas apareciam nos artigos e relatórios científicos para que pudessem compreender de que maneira o diálogo da 
teoria com a experiência da pesquisa e do processo de formação na escola vai se construindo.

Em outra oportunidade, na ATPC de 29/05/2012, levamos a transcrição do encontro anterior e projetando o texto com o apoio do datashow pudemos recuperar grande parte das discussões travadas em torno do papel dos professores como mediadores de leitura em sala de aula e as expectativas com relação ao papel dos pais e esforço dos alunos. A experiência de valorizar e compartilhar a audiogravação, e reconhecer a potencialidade do vivido e registrado para ser melhor pensado, além de desmistificar a presença do gravador como intruso contribuiu para que o debate da semana anterior avançasse.

O aprofundamento da discussão só foi possível com a retomada do registro transcrito. O diálogo abaixo é representativo do esforço do grupo para negociar sentidos, compreender o sentido do trabalho da escola, da relação com os pais, entre si.

Prof́a Maria (Professora Coordenadora): Sabe, ontem veio a mãe de um aluno da quinta série e no caderno estava escrito que tal mãe estava sendo chamada devido à negligência familiar. Essa mãe não veio em uma série de convocações, mas ontem ela ficou esperando na saída e eu fui conversar com ela. Ela me disse: - Como podem chamar-me de negligente?! Eu seria negligente se meu filho não tivesse o que comer, mas eu trabalho das seis da manhã às oito da noite para colocar comida na mesa para meu filho, então, onde estou sendo negligente?! Então, pessoal, isso é algo muito sério!

Profá Sueli (Português): "É sério, pois nós temos tudo pessoal! Pensem comigo, nós temos tudo!

Profá Maria (Professora Coordenadora): Nós achamos que essa mãe irá acompanhar caderno, leitura, etc., mas ela está preocupada com...

Profá Sueli (Português): O arroz e o feijão!

Pesquisador 1: Ela está preocupada com a sobrevivência!

Profa Maria (Professora Coordenadora): Ela vive sozinha com três filhos e ela me disse: - Como vocês podem chamar-me de negligente se nunca falta para meus filhos o que comer?! Ora, ela esta fazendo seu papel! Vou falar que ela está errada pessoal?

Prof́a Sueli (Português): Para nós, muitas coisas são fáceis, não?

Profa Maria (Professora Coordenadora): Então, nós achamos que olhar o caderno do filho, ler um bilhete etc., são as coisas mais importantes do mundo e achamos que ela é negligente porque não fez essas coisas...

Pesquisador 1: É a escala de prioridade de cada um.

Profá Sueli (Português): Exatamente.

Profó Paula (Matemática): Mas então qual é o propósito da escola?

(...)

Profa Sueli (Português): É muito duro! Eu olho para nossos alunos e digo que eles são heróis! Nossos alunos são heróis!

Profa Angela (Matemática): Mas se eles precisam de exemplos, daremos justamente o exemplo do coitado?

[muitos falaram ao mesmo tempo]. 
Prof. Valter (Geografia): Não, não é oferecer o exemplo do coitado...

Profa Angela (Matemática): É sim! Porque a todo o momento estamos a dizer: Ah! Coitado! Ai que dó ver a situação que ele está!

Como pode se depreender dos diálogos apresentados, professores e pesquisadores, como sujeitos ativos, se educam, se organizam, "apropriando-se, para a ação, de um saber construído coletivamente" (SCHIMIDT, 2006, p.15) nas relações de formação e pesquisa.

\begin{abstract}
A interlocução que se estabelece no trabalho de campo tem como horizonte a construção do sentido da experiência de um outro próximo ou distante. Nesta visão, o interlocutor, representante do "pólo pesquisado", é portador e porta-voz da experiência e o pesquisador pode estar na posição de recolhedor da experiência, mediador, tradutor ou intérprete. No diálogo, contudo, o interlocutor transmite sua experiência, interpretando-a, de tal forma que também funciona como tradutor e mediador de sua posição social, cultural e subjetiva para o pesquisador. $O$ jogo de identidades e alteridades que se dão a conhecer mutuamente, afirmando-se, mas, ainda, deslocando-se e transformando-se, participa da mobilidade destes lugares ou funções de tradução e mediação (SCHIMIDT, 2006, p.36).
\end{abstract}

E é nesse jogo de identidades e alteridades que a combinação de interpretações e a composição de saberes, segundo Schimidt (2006), permite atribuir sentido à investigação e aos encontros que possibilitam pensar possibilidades e desdobramentos no cotidiano da escola e da própria pesquisa.

Nessa perspectiva, faz sentido pensarmos nessas ATPCs como comunidades interpretativas, ou seja, como oportunidades de articulação de pontos de vista, vozes e diferenças (SCHIMIDT, 2006) onde as funções de interlocutor e de intérprete, na relação entre professores e pesquisadores, vai sendo alternada num esforço mútuo de compreensão das exposição de modos de sentir e de pensar.

Embora sejamos nós, pesquisadores, a partir dos nossos registros de campo e orientados por nossos compromissos éticos e políticos, quem iremos redigir o texto síntese da pesquisa, as interpretações, representações e imagens da alteridade, segundo Schimidt (2006), podem se constituir como ensaio ou exercício de uma comunidade interpretativa, instituindo não só a autoria como a coautoria.

\title{
3 Considerações finais
}


Valorizar a pesquisa no cotidiano escolar e o intercâmbio entre professores da universidade e professores da escola básica supõe uma reflexão permanente sobre os encaminhamentos metodológicos que sustentam essa relação. Não basta somente obter autorização da direção da escola para acompanhar ou coordenar os momentos de trabalho coletivo ou outras práticas pedagógicas, tampouco o consentimento dos profissionais da escola.

Para viabilizar um trabalho de pesquisa e formação em regime de colaboração na escola, instituindo uma comunidade interpretativa e aproximando as práticas de pesquisa do cotidiano de formação nas ATPCs, é necessário construir vínculos de confiança entre pesquisadores e professores.

Isso se dá, na nossa perspectiva, na medida em que os professores compreendem o sentido na pesquisa, seus objetivos, pressupostos, compromissos. Receber a cópia do projeto de pesquisa, ter acesso às transcrições dos encontros, ter a oportunidade de conhecer as publicações dos pesquisadores e a maneira como tratam as informações levantadas na escola e com os professores nos seus relatórios e artigos são cuidados importantes que devem ser levados em consideração.

A partir dessas ações e da disponibilidade recíproca de estar, compartilhar e aprender juntos, pesquisadores e professores da escola básica podem ampliar o conhecimento e a compreensão da realidade escolar e dos compromissos da universidade, redimensionar suas ações e renovar suas práticas de ensino e pesquisa na perspectiva do desenvolvimento profissional.

Mattos (1995, p.113) destaca que "ambos, professores e pesquisadores, possuem as peças do quebra-cabeça, mas as peças são diferentes, portanto, temos que confiar no conhecimento mútuo sobre determinado tema, também de interesse mútuo".

Entendemos que a formação produzida no grupo e por meio do trabalho coletivo pode ser (re)orientadora para as práticas pedagógicas da escola e da própria pesquisa quando valorizam a combinação de interpretações e a composição de saberes, articulando pontos de vista, vozes e diferenças.

\section{Referências}


ALMEIDA, L. R. O relacionamento interpessoal na coordenação pedagógica. In: PLACCO, V. M. N. S.; ALMEIDA, L. R. (Orgs.) O coordenador pedagógico e o espaço de mudança. São Paulo: Loyola, 2001. p. 67-80.

ALMEIDA, L. R. A dimensão relacional no processo de formação docente. In: BRUNO, E. B. G.; ALMEIDA, L. R.; CHRISTOV, L. H. S. (Orgs.). O coordenador pedagógico e a formação docente. São Paulo: Loyola, 2000. p. 77-88.

CHRISTOV, L. H. S. Teoria e prática: o enriquecimento da própria experiência. In: GUIMARÃES, A. A.; MATE, C. H.; BRUNO, E. B. G. (Orgs.). O coordenador pedagógico e a educação continuada. São Paulo: Loyola, 1998. p. 31-34.

CUNHA, R. C. O. B.; ARAGÃO, A. M. F. A interlocução como experiência de formação docente. Revista Comunicações, Piracicaba, v. 17, n. 2, p. 7-19, jul. dez. 2012.

CUNHA, R. C. O. B.; PRADO, G. V. T. Sobre importâncias: a coordenação e a co-formação na escola. In: PLACCO, V. M. N. S.; ALMEIDA, L. R. O coordenador pedagógico e os desafios da educação. São Paulo: Loyola, 2008. p.37-50.

CUNHA, R. C. O. B.; PRADO, G. V. T. Formação centrada na escola, desenvolvimento pessoal e profissional de professores. Revista de Educação PUC-Campinas, Campinas, n. 28, p. 103113, jan./jun. 2010.

DAMIANI, M. F. Entendendo o trabalho colaborativo em educação e revelando seus benefícios. Educar, Curitiba, n. 31, p. 213-230. 2008.

DIAS-DA SILVA, M. H. G. F. A cultura da escola pública e a pesquisa colaborativa com professores: alguns conflitos. Perspectiva, Florianópolis, v.19, n.1, p.149-165, jan./jun. 2001.

DUARTE, R. Pesquisa qualitativa: reflexões sobre o trabalho de campo. Cadernos de Pesquisa, São Paulo, n. 115, p.139-154, mar. 2002.

GIOVANI, L. M. Do professor informante ao professor parceiro: reflexões sobre o papel da universidade para o desenvolvimento profissional de professores e as mudanças na escola. Caderno Cedes, Campinas, v.19, n.44, p.46-58, abr. 1998.

LÜDKE, M. (Coord.). O que conta como pesquisa? São Paulo: Cortez, 2009.

MATTOS, C. L. G. Etnografia Crítica de Sala de Aula: o Professor Pesquisador e o Pesquisador Professor em Colaboração. Revista Brasileira de Estudos Pedagógicos, Brasília, v.76, n.182/183, p.98-116, jan./ago. 1995.

PETIT, M. Os jovens e a leitura: uma nova perspectiva. 2ed. São Paulo: Editora 34, 2009.

PETIT, M. A arte de ler: ou como resistir à adversidade. São Paulo, Editora 34, 2010.

SACRISTÁN, J. G. O currículo: uma reflexão sobre a prática. 3ed. Porto Alegre: Artmed, 1998. 
SACRISTÁN, J. G.; PÉREZ GÓMEZ, A. I. Compreender e transformar o ensino. Porto Alegre: ArtMed, 1998.

SCHIMIDT, M. L. S. Pesquisa Participante: Alteridade e Comunidades Interpretativas. Revista de Psicologia USP, São Paulo, v. 17, n.2, p. 11-41, jun. 2006.

ZEICHNER, K. Para além da divisão entre professor-pesquisador e pesquisador acadêmico. In: GERALDI, C. M. G.; FIORENTINI, D.; PEREIRA, E. M. A. (Orgs). Cartografias do trabalho docente: professor(a)-pesquisador(a). Campinas: Mercado de Letras, 1998. p.207-236.

Enviado em Janeiro/2013

Aprovado em Junho/2013 